\title{
Spectroscopic Studies on Binding Interactions of Cationic Porphyrin Derivatives with Double Helical d(CGCGAATTCGCG) 2
}

\author{
Seokjoo Hong and Sungho Huh* \\ Department of Biochemistry, Chungnam National University, Daejon 305-764, Korea \\ Received November 13, 2002
}

Key Words : DNA oligomer, Porply rin derivative, Binding, Spectroscopy. NMR

\begin{abstract}
DNA plays an important role in storage and expression of genetic informations in a cell. In order to cary out its biological function. DNA should interact with various proteins such as DNA polymerases. RNA polymerases. and many kinds of the regulatory molecules. Various ligands can also interact with DNA and regulate its function, and some of then are used as antitumor or antibiotic agents. ${ }^{1,2}$ Cationic porphyrins containing four pyrrole rings and conjugated double bonds have also been reported to be able to interact with DNA to form DNA-porphyrin complexes and cause cleavage of DNA with the aid of irradiation of laser or UV light. ${ }^{3-6}$ In addition. porphyrins remain longer in cancer cells than normal cells after injection. Because of these unique properties. some cationic porphyrins have been used as the photochemotherapy agents to treat cancer ${ }^{7 \cdot 11}$ Recently. it has been reported that tumor necrosis and inhibition of telonterase due to stabilization of telomere can be induced by interaction
\end{abstract} of a cationic porphy rin derivative. ${ }^{11.15}$

Cationic porphyrins are very versatile in the number of positive charges and the number as well as the types of substituents. and the kind of metal ions coordinated at porphyrin center. $^{16.18}$ Consequently. they show various interacting patterns in binding to DNA. depending on the followings: (i) the number and position of positive charges. (ii) the position. the type, and the number of the substituents at the porphyrin ring and (iii) the base sequence of DNA. ${ }^{19.21}$ Presence or absence and the type of the coordinated metal ion have also an important effect on the binding pattern.2.23 Based on these facts. all of Coulombic hydrophobic and steric interactions might be involved in binding of porphỵrins to DNA. The favorable site for intercalation and groove binding of cationic porphyrrins to DNA has been reported to be $5^{\prime}-\mathrm{CG}-3^{\prime}$ and 5 '-AT-3' sites. respectively ${ }^{24.25}$ Thus. meso-tetrakis-(4$N$-methỵlpy ridiniumyl)porphỵrin(T4MPyP), Cu(II)T4MPyP and Ni(II)T4MPyP are reported to bind to the 5'-CG-3' sites. but meso-tetrakis-(2-N-methỵlpyridiniumyl)porphỵrin(T2MPỵP). Zn(II)T4MPyP. Fe(III)T4MPyP. and Co(III)T4MPyP do not $^{26}$ Intercalation of T4MPỵP occurs at 5'-CG-3' sites of poly $(\mathrm{dG}-\mathrm{dC})$, but T4MPyP is also able to bind to $5^{\prime}-\mathrm{AT}-3^{\prime}$ sites of poly (dA-dT) in the groove or in the manner of outside stacking along the phosphate backbone chain. Very recently X-ray structures of some porphyrin-DNA complexes has been reported. ${ }^{77}$ According to the X-ray structure of $\mathrm{Cu}$ (II)T4MPyP-d(CGATCG) 2 adduct. Cu(II)T4MPyP was regarded to hemiintercalate at the 5 '-CG-3' steps of d(CGA-
TCG):.$^{8}$ And the X-ray structure of Ni(II)T4MPyP-d(CCT$A G G$ ) 2 showed that $\mathrm{Ni}(\mathrm{II}) \mathrm{T} 4 \mathrm{MPy} P$ was not intercalated into DNA. but was stacked onto the two ends of DNA duplex. ${ }^{\text {t9 }}$ A few NMR studies on porphyrin-DNA adducts have also been reported. ${ }^{3 i-32}$ The proposed NMR structure of the T4MPyP-d(GCATGTGC), adduct shows that T4MPyP is sandwitched between two cis Watson-Crick 5'-CG-3' base pairs. but this structure is still disputable..$^{32}$

We report here the NMR and spectroscopic analysis of interactions between d(CGCGAATTCGCG) ent cationic porphyrins. meso-tetrakis-(4- $N$-methylpyridiniumyl)porplyyin(T4MPyP) and meso-tetrakis-( $N, N, N$-trimethylanilinium-4-yl)porphyrin(TMAP). T4MPy used in the research is chemically stable in the absence of light. maintains the monomeric state and can be used as a photosensitizer agent. ${ }^{3 z}$ TMAP has an identical porphyrin ring but bulkier substituent groups on the periphery of the porphyrin ring. Thus, comparison of two porphyrins in the binding interaction with DNA is thought to be important for understanding the mechanism of interaction between porphyrins and DNA in detail. The DNA oligomer d(CGCGAATTCGCG) was synthesized with an ABI 391 PCR MATE DNA synthesizer by $\beta$-cyanoethyl-phosphoramidite chemistry in solid phase. The synthesized DNA was purified with the dialysis tube with the molecular cutoff range of 2.000 , and a Chelex-100 column and then lyophilized (Figure 1A). All DNA solutions were prepared in $20 \mathrm{mM}$ sodium phosphate buffer ( $\mathrm{pH} 6.92$ ) containing $100 \mathrm{mM}$ of $\mathrm{NaCl}$. This sequence contains both of 5'-CG-3' and 5'-AT-3'. hence the dependence of binding porphyrins to DNA on the base sequence can be monitored. Water soluble. tetracationic porphyrins of meso-tetrakis-(4- $N$-methỵlpyridiniumyl) porphyrin (T4MPyP) tosylate and meso-tetrakis-(N.N.N-trimethylanilinium-4-yl) porphyrin (TMAP) tosylate were purchased from Sigma Aldrich $\mathrm{Co}$. and were used without further purification (Figure IB).

UV absorption spectra in the Soret band region of each T4MPyP and TMAP are shown in Figure 2, as a function of the [porphyrin] : [DNA] molar ratio. Both of two porphyrins showed substantial hypochromicity $(\mathrm{H})$ up to $50 \%$ decrease in the intensity of the Soret band upon binding to a $\mathrm{d}$ (CGCGAATTCGCG) 2 duplex. Binding of each of TMAP and T4MPyP to the d(CGCGAATTCGCG), duplex also caused the red shift of the Soret band by $10 \mathrm{~nm}$ and $16 \mathrm{~nm}$. respectively. upon adding the DNA oligomer up to $2: 1$ of 
(A)

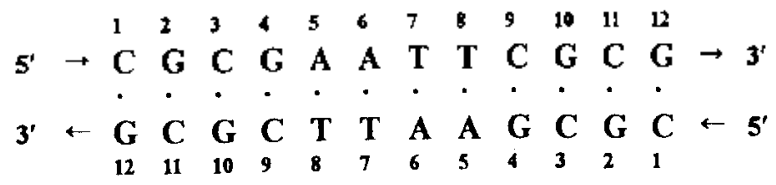

(B)<smiles></smiles>

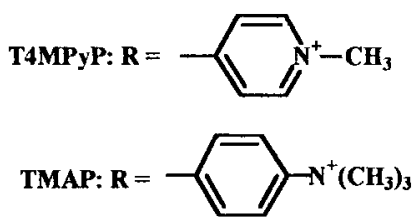

Figure 1. The base sequence of DNA oligomer (A) and the chemical structure of cationic porphyrins $(\mathrm{B})$.

the [porphyrin] : [DNA] molar ratio (Table 1).

This was consistent with the result reported elsewhere ${ }^{-4}$ and represented that interaction with the d(CGCGAATTCGCG): duplex caused the environment of T4MPyP to be more hy'drophobic than that of TMAP. Consequently. the porphyrin ring of T4MPy $\mathrm{P}$ was considered to be positioned in the major or minor groove near to base pairs of the $\mathrm{d}$ (CGCGAATTCGCG) duplex. In addition, the Soret band of TMAP showed an isosbestic point clearly. but that of T4MPyP did not. which indicated that the former showed the single binding mode but the latter showed a heterogeneous binding mode.

In circular dichroism (CD) spectra obtained as a function of the [porphyrin] : [DNA] molar ratio. the induced CD signals are shown in the visible range from 410 to $430 \mathrm{~mm}$ for both of T4MPyP and TMAP (Figure 3). The results represented that each porphyrin interacted with the $\mathrm{d}(\mathrm{CGCGAATTCGCG})$ _ duplex because free porphyrin do not cause any $C D$ signal. The negatively induced $C D$ signals for T4MPyP and the excitonic CD signals for TMAP represented intercalating binding and groove or outside binding with self stacking respectively:

Two porphyrins increased thermal stability of the $\mathrm{d}$ (CGCGAATTCGCG) 2 duplex by 5 of melting temperature $\left(\mathrm{T}_{\mathrm{m}}\right)$. upon binding at $2: 1$ of [porphỵrin] : [DNA] molar ratio

Table 1. Spectroscopic data for porphyrins(T4MPYP and TMAP) bound to the DNA oligomer

\begin{tabular}{c|ccc}
\hline Samples & $\Delta \lambda$ & $H$ & Induced CD \\
\hline $\begin{array}{c}\text { AATT-T4MPyP } \\
\text { complex }\end{array}$ & $16 \mathrm{~nm}$ & $53 \%$ & $420 \mathrm{~nm}(-)$ \\
$\begin{array}{c}\text { AATT-TMAP } \\
\text { complex }\end{array}$ & $10 \mathrm{~nm}$ & $50 \%$ & $414 \mathrm{~nm}(+), 424 \mathrm{~nm}(-)$ \\
\hline
\end{tabular}
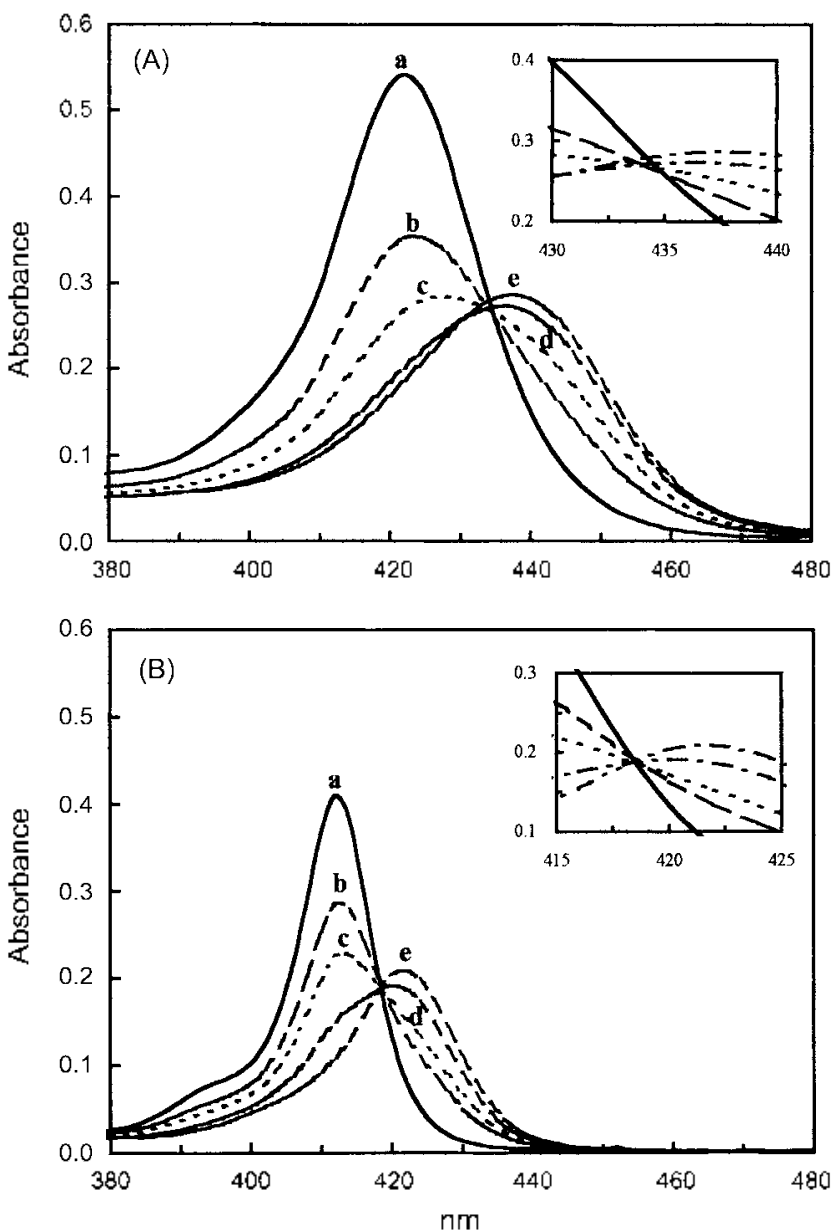

Figure 2. Absortion spectra in the Soret region of T4MPyP(A) and $\operatorname{TMAP}(\mathrm{B})$ at various molar ratios( $\mathrm{r}$ ) of [porphyrir]/[DNA]. Each insertion is prepared in order to make sure the existence of the isosbestic point. (a) free porphyrin, (b) $\mathrm{r}=0.3$, (c) $\mathrm{r}=0.5$, (d) $\mathrm{r}=1,0,(\mathrm{e}) \mathrm{r}=2.0$.

(Table 2). Binding of T4MPyP increased $\mathrm{T}_{\mathrm{m}}$ of the duplex by $2^{\circ} \mathrm{C}$ at $1: 1.5^{\circ} \mathrm{C}$ at $2: 1.5^{\circ} \mathrm{C}$ at $3: 1$ of [porphyrin] : [DNA] molar ratio. But TMAP increased $\mathrm{T}_{\mathrm{m}}$ of the same DNA duplex $4{ }^{\circ} \mathrm{C}$ at $1: 1,5{ }^{\circ} \mathrm{C}$ at $2: 1$, and $5^{\circ} \mathrm{C}$ at $3: 1$ of [porphyrin] : [DNA] mole ratio upon binding to DNA oligomer. Binding of T4MPyP increased $T_{m}$ of the duplex gradually with increase of the amount of porphyrin. but in case of TMAP. $T_{m}$ of the duplex increased maximally at $1: 1$ of [porphyrin] : [DNA] molar ratio and extra addition of this compound did not caused further increase in $T_{m}$ of the DNA duplex any more. Based on the UV melting result. TMAP is considered to bind to the d(CGCGAATTCGCG): duplex through Coulombic interaction between the negative charge on phosphodiester chain and the positive charge on substituent of porphyrin. and the second TMAP might be inhibited to bind to same DNA duplex. The data from UV mixing between each porphyrin and the d(CGCGAATTCGCG) : duplex revealed that TMAP and T4MPYP formed the stable complex with $1: 1$ and $1.3: 1$ of [porphyrin] : [DNA] molar ratio, respectively. and were well consistent with UV melting data mentioned previously.

Figure 4 shows the imino proton region of the ${ }^{~} \mathrm{H}$ NMR 

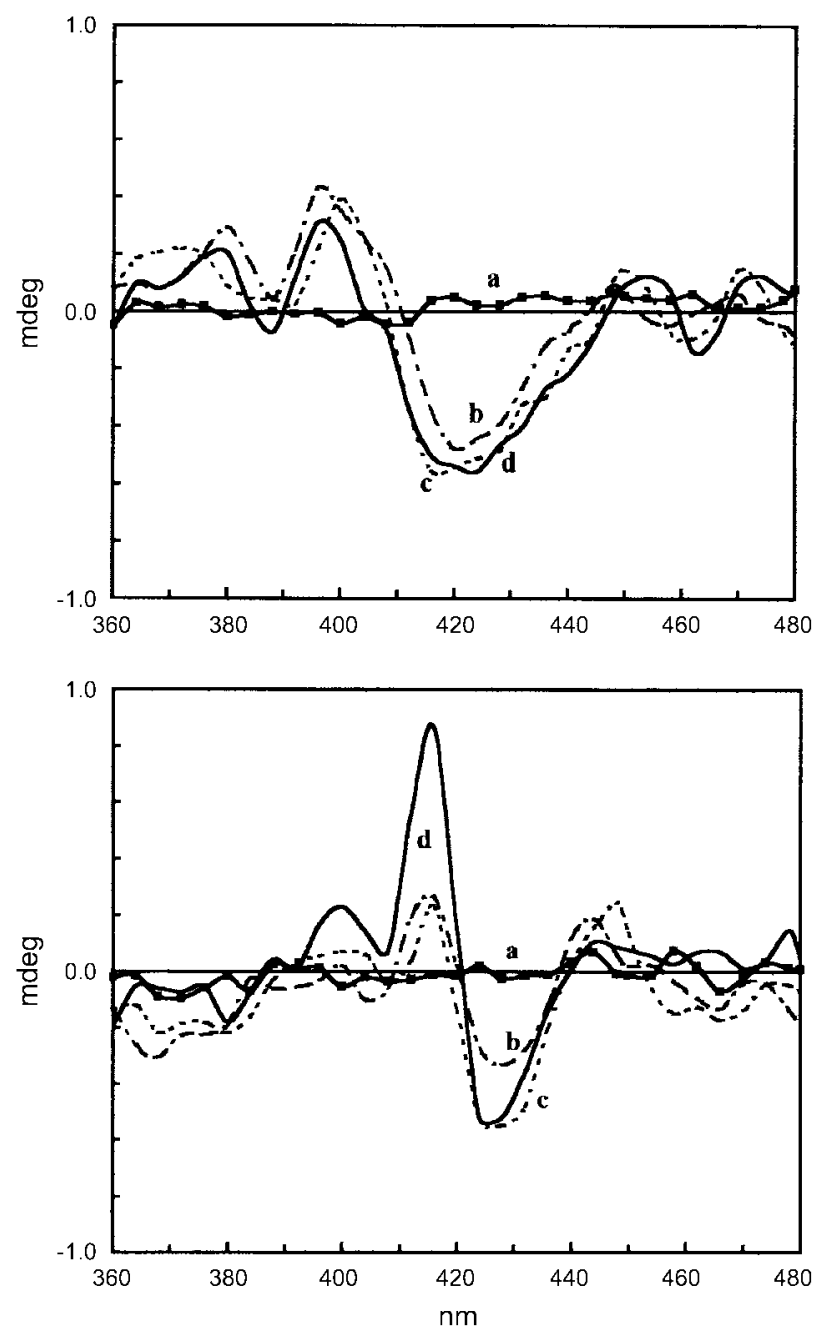

Figure 3. Induced CD spectra of T4MPrP(A) and TMAP(B) at various molar ratios( $\mathbf{r}$ ) of [porphyrin]/[DNA]. (a) free porphyrins, (b) $\mathrm{r}=2.0$, (c) $\mathrm{r}=1.0$, (d) $\mathrm{r}=0.5$

Table 2. Melting Temperature $\left(\mathrm{T}_{m}\right)$ of $\mathrm{d}(\mathrm{CGCGAATTCGCG})_{2}$ and its complex with porphyrin at various mole ratio(r)

\begin{tabular}{c|cc}
\hline $\begin{array}{c}\text { Samples } \\
\text { [porphyrins]/[DNA] }\end{array}$ & $\begin{array}{c}\text { AATT-T4MPyP } \\
\text { complex, }{ }^{\circ} \mathrm{C}\end{array}$ & $\begin{array}{c}\text { AATT-TMAP } \\
\text { complex; }{ }^{\circ} \mathrm{C}\end{array}$ \\
\hline 0.0 & 45 & 45 \\
1.0 & 47 & 49 \\
2.0 & 50 & 50 \\
3.0 & 51 & 50 \\
\hline
\end{tabular}

spectra as a function of [porphỵrin] : [DNA] molar ratio. Binding of T4MPYP caused the gradual broadening effect on guanine imino resonance signals. especially on guanine 2 and 10 , with the increase of [porphyrin] : [DNA] molar ratio. and they could not be observed at higher [porphyrin] : [DNA] mole ratio than $0.5: 1$ because of serious broadening effect on guanine imino protons. And guanine imino protons also showed observable upfield shift in the chemical shifts at $0.5: 1$ of the [porphyrin] : [DNA] molar ratio. This indicated that T4MPy'P might bind at 5'-GCG-3' of a d(CGCGAATT$\mathrm{CGCG})_{2}$ duplex in the manner of intercalation. In contrast.

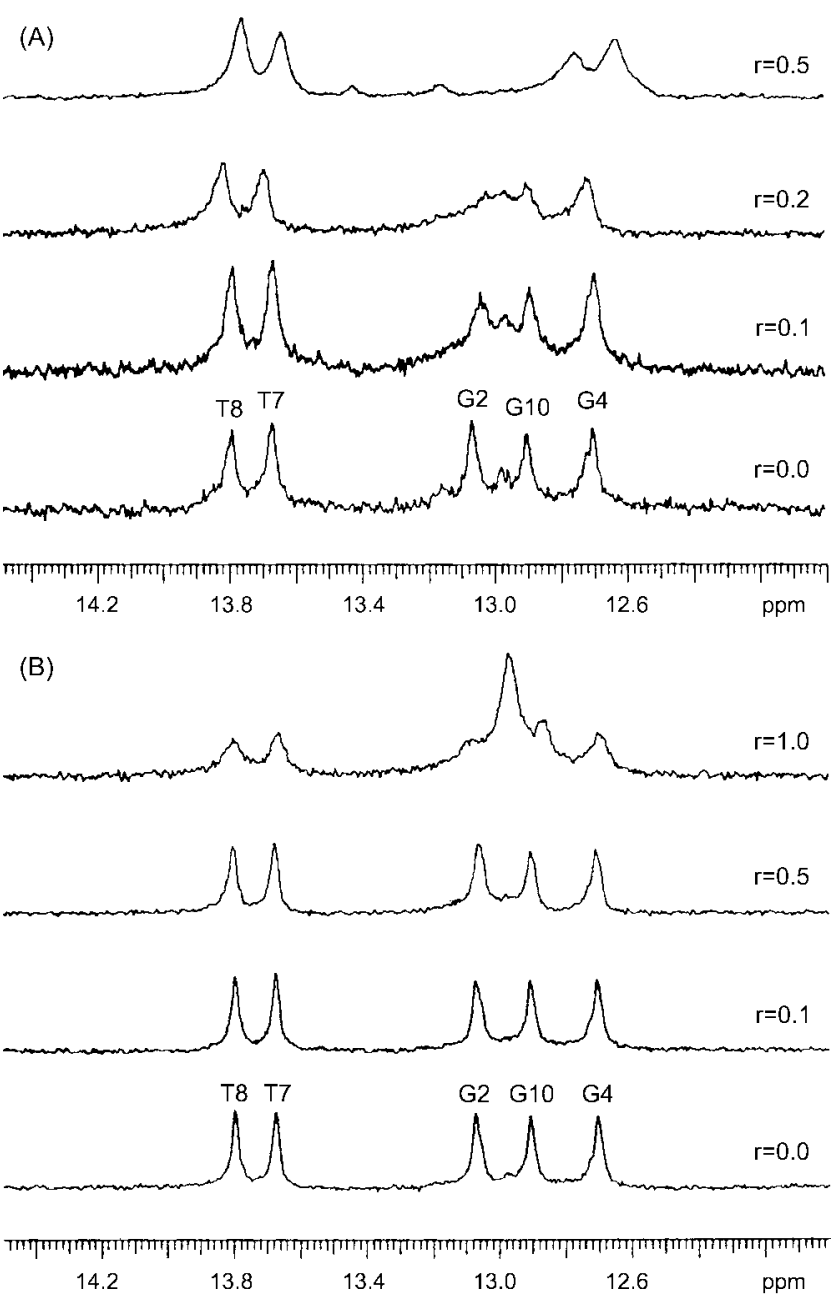

Figure 4. Imino proton resonance signals of d(CGCGAATTCG$C G)_{2}$ at various [porphyrin]/[DNA] molar ratios(r) of T4MPyP (A) and TMAP $(B)$.

TMAP did not cause observable change in chemical shifts of imino proton signals and any broadening effect up to $0.5: 1$ of [porphyrin] : [DNA] molar ratio. but caused serious broadening effect on every imino proton of bases at $1: 1$ of [porphyrin] : [DNA] mole ratio. Hence TMAP showed a different binding mode from that of T4MPy.

Figure 5 shows ${ }^{31} \mathrm{P}$ NMR spectra of a d(CGCGAATTCGCG) 2 duplex(A). a d(CGCGAATTCGCG) 2 duplex-T4MPyP complex(B), and a d(CGCGAATTCGCG) = duplex-TMAP complex(C). Both porphyrins caused broadening of ${ }^{31} \mathrm{P}$ resonance signals upon binding but TMAP broadened more significantly ${ }^{31} \mathrm{P}$ resonances of $5^{\prime}$-AATTC-3' in the middle part of the model DNA. In addition. T4MPy'P caused more or less upfield shift upon binding to a d(CGCGAATTCGCG) : duplex. but TMAP did not. This might be due to perturbation in the phosphodiester chain caused by T4MPyP. Therefore the binding mode of T4MPy might have two characteristics. that is partial intercalation as well as the ionic interaction between the phosphate negative charge of DNA and the positive charge of T4MPyP.

According to the results obtained from this research. T4MPy $\mathrm{P}$ is regarded to bind to double helical d(CGCGAA- 


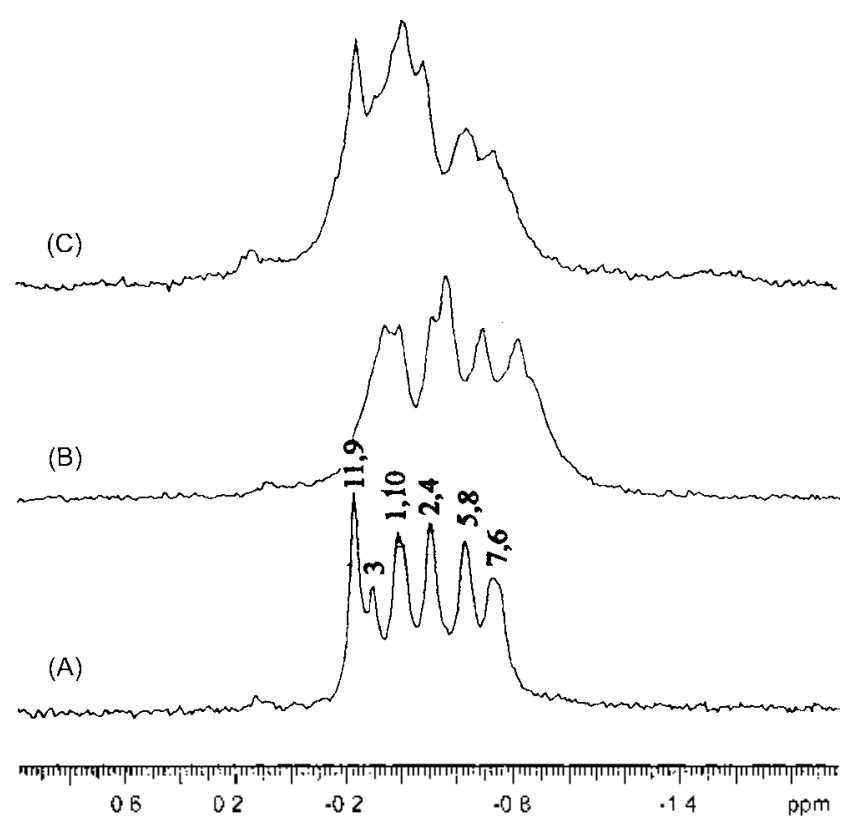

Figure 5. ${ }^{31} \mathrm{P}$ NMR spectra of double helical d(CGCGAATTCGCG) 2 (A), its complex with T4MPYP (B), and its complex with TMAP (C)

TTCGCG) s primarily at the 5'-GCG-3' site through not only the Coulombic interaction between opposite charges on DNA and T4MPyP. but a weak intercalation of the porphyrin ring until the molar ratio of [porphyrin] : [DNA] became 0.5 . In contrast. TMAP is regarded to bind to d(CGCGAATTCGCG) 2 at A-T pair rich site along the phosphodiester chain only through the Coulombic interaction between opposite charges on DNA and TMAP. until the molar ratio of [porphyrin] : [DNA] became 1.0. For more detailed informations. more works with two-dimensional NMR data are under progress.

\section{References}

1. Searle. M. S. NaR in Drig Design: CRC Press: Boca Raton, FL. 1996: $\mathrm{p} 377$

2. Sobell. H. M.: Tsai, C. C.: Jain. S. C.: Gilbert. S. G. J. Mol. Biol. 1977. 114.333 .

3. Mestre. B.: Jakobs. A.: Pratviel. G.: Meunier. B. Biochemishy 1996. 35.9140

4. Ding L.: Moghadam. G. E.: Melnier. B. Biochentisty 1990. 29. 7868.

5. Dabrowiak J. C.: Ward, B: Goodisman, J. Biochemistry 1989, 28. 3314.
6. Bemadou. J.: Pratviel. G.: Bennis. F.: Girardet, M.: Meunier, B. Biochemisty 1989. 28. 7268 .

7. Villanueva. A.: Caggiari. L.: Iori. G.: Milanesi. C. J. Photochem. Photobiol B: Biol 1994. 23. 49.

8. Henderson. B. W. Fingar. W. H. Photochent Photobiol 1989. 49. 299.

9. Dougherty, T. J. Photochem. Photobiol 1993, 58,895 .

10. Dougherty, T. J.: Gomer, C. J.; Henderson, B. W.: Jori, G.: Kessel, D.: Korbelik. M: Moan. J.: Peng. Q. J of National Cancer Institute 1998. 90.889

11. Anantha. N. V: Azam1. M.: Sheardy. R. D. Biochemistry 1998. 37. 2709.

12. Wheelhouse. R. T.: Sun. D.: Han, H.; Han, F. X: Hurley, L. H. J. An Chen. Soc. 1998, 120.3261.

13. Fedorofĩ. O. Y.: Ran1gan. A.: Chemeris. V. V: Hurley. L. H. Biochemisny 2000. 39. 15083.

14. Arthanari. H.: Basu. S.: Kawan1o. T. L.: Bolton. P. H. Kucleic Acids Res. 1998. 26, 3724.

15. Hac, I: Trent, J. O : Chowdhry. B. Z.: Jenkins, T. C. J. Am. Chent. Soc. $1999,121,1768$

16. Sari. M. A.: Battioni. J. P.: Dupre. D.: Mansuy. D.: LePecq. I. B. Biochemisty 1990. 29. 4205.

17. Carvlin. M. T.: Fiel. R. T. Kucleic Acids Res. 1983. 11.6121.

18. Carvlin. M. J.: Mark. E.: Fiel, R. Nucleic Acids Res. 1983, II. 6141.

19. Mukundan. N. E.; Pethö, G.; Dixon, D. W.; Marzilli, L. G. Ihorg Chem 1995.34 .3677 .

20. Lee. S.: Jeon. S.: Kim. B.: Han. S.: Jang. H.: Kim. S. Biophusical Chemistry 2001.92.35.

21. Sari. M. A.; Battioni, J. P.: Dupre, D.: Mansuy. D.: Lepecq. J. B. Biochem. Biophs Res Commm 1988. 37, 1861.

22. Strickland, J. A.; Marzilli. L. G.; Wilson, W. D.: Zon. G. Thong Chem 1989. 28.4191.

23. Tjahjono. D. H.: Minna. S.: Akutsu. T.: Yoshioka. N.: Inoule. H. $J$. of horganic Biochenistry 2001. 85. 219.

24. Ford, K. G.: Pearl. L. H. Neidle. S. Nucleic Acids Res. 1987, 15. 6553 .

25. Ford. K.: Fox. K. R.; Neidle. S.; Waring. M. J. Nicleic Acids Res. 1987. 15.2221

26. Pasternack. R. F.: Gibbs. E. J.: Villafranca. T. I. Biochemistry 1983. 22. 2406

27. Hui. X: Gresh. N.; Pullman, B. Nucleic Acids Reseurch 1990. 18. 1109.

28. Lipscomb. L. A.; Zhou, F. X.; Presnell. S. R.: Woo, R. J.: Peek. M E.: Plaskon. R. R.: Williams. L. D. Biochemisoy 1996. 35. 2818.

29. Bennett. M.: Krah. A.: Wien. F:: Garmant. E.: Mckenna. R. Sandersont. M.: Neidle. S. Proc. Natl. Acd. Sci. USA 2000. 97. 9476.

30. Marzilli, L. G.; Banville. D. L.: Zon. G.; Wilson, W. D. J. An. Chent Soc. 1986, 108. 4188

31. Fedoroff. O. Y: Rannan. A.: Chemeris. V. V: Hurley: L. H Biochemistoy, 2000. 39. 15083.

32. Strickland. T. A.: Marzilli. L. G.: Wilson. W. D.: Zon1. G. Ihorg. Chent $1989,28,4191$.

33. Guliaev. A. B.: Leontis. N. B. Biochentism $1999,38,15425$. 